\title{
Sleeping on an Anti-Wrinkle Pillow Reduces Facial Wrinkles: Results from an Anatomical Study
}

\author{
Borut Poljsak ${ }^{1}$, Aleksandar Godic ${ }^{2}$, Rok Fink ${ }^{1}$, Martina Oder ${ }^{1}$, Tomaz Lampe', \\ Raja Dahmane ${ }^{3,4 *}$ \\ ${ }^{1}$ Laboratory for Oxidative Stress Research, Faculty of Health Sciences, University of Ljubljana, Ljubljana, \\ Slovenia \\ ${ }^{2}$ Department of Dermatology, Cambridge University Hospitals, Addenbrooke's Hospital, Cambridge, UK \\ ${ }^{3}$ Biomedicine in Health Care Division, Faculty of Health Sciences, University of Ljubljana, Ljubljana, Slovenia \\ ${ }^{4}$ Faculty of Medicine, Institute of Anatomy, Ljubljana, Slovenia \\ Email: raja.dahmane@guest.arnes.si
}

Received 3 March 2015; accepted 30 March 2015; published 2 April 2015

Copyright (C) 2015 by authors and Scientific Research Publishing Inc.

This work is licensed under the Creative Commons Attribution International License (CC BY).

http://creativecommons.org/licenses/by/4.0/

(c) $\underset{\mathrm{EY}}{\mathrm{E}}$ Open Access

\section{Abstract}

Background: A special pillow was designed to redistribute mechanical stress during sleeping in order to slow down the formation of facial skin wrinkles. Objective: To investigate whether sleeping on a specially designed pillow reduces facial skin wrinkles. Participants and Methods: A 28-day pilot study was carried out in which fifteen healthy female volunteers aged 23 - 55 years (mean age $35.6 \pm 8.5$ ) slept on an antiwrinkle pillow. Evaluation of facial wrinkles was conducted before commencing the study $\left(T_{0}\right)$, following at 14 days $\left(T_{14}\right)$, and at 28 days $\left(T_{28}\right)$ when the study ended. Wrinkle density was assessed by computerized analysis of $2 \mathrm{D}$ images of participants' faces. Results: A statistically significant decrease in wrinkle density was detected while smiling around both eyes, around the right eye in a relaxed facial expression, on average in all observed facial areas, around the left periorbital area in participants who predominantly slept on their left side of the body, but not on the frontal area. Limitations: A 3D camera could be used to better visualize and analyze wrinkle density. Conclusions: Sleeping on the specially designed pillow reduces facial wrinkles.

\section{Keywords}

Sleeping, Wrinkles, Facial Anatomy, Anti-Wrinkle Pillow

\footnotetext{
${ }^{*}$ Corresponding author.
}

How to cite this paper: Poljsak, B., Godic, A., Fink, R., Oder, M., Lampe, T. and Dahmane, R. (2015) Sleeping on an AntiWrinkle Pillow Reduces Facial Wrinkles: Results from an Anatomical Study. Forensic Medicine and Anatomy Research, 3, 48-56. http://dx.doi.org/10.4236/fmar.2015.32010 


\section{Introduction}

The facial skin responds to repetitive contractions of underlying muscles while smiling, frowning, and other physical movements. Usually, by the mid-twenties, most people begin to notice faint lines on the forehead, between the eyebrows, in the nasolabial folds and the periorbital areas [1] [2]. Early wrinkles are seen at first during facial expression, whereas persistent wrinkles, such as crow's feet, glabellar frown lines and forehead transverse lines, appear later [3]. Facial expressions are produced by 43 muscles, which can produce over 100,000 variations [1]. The palpebral and orbital components of the orbicularis oculi muscle surround the pretarsal and preseptal aspects and function essentially as the sphincter muscle of the eyelid, which is responsible for blinking and gentle eye closure. Its direct antagonist is the Levator palpebrae muscle. Some of the fibres of the superior medial orbital component function as depressors of the medial eyebrow, whereas the superior lateralorbital orbicularis acts partly as a depressor of the lateral eyebrow. Forceful mechanical pressure on the orbital component induces concentric folds emanating from the lateral canthus, resulting in lateral canthal lines, or "crow's feet”. The zygomaticus major muscle forms the angle of the mouth superiorly, laterally and posteriorly, in a similar manner as seen in laughing, smiling and chewing. The zygomaticus minor muscle functions as one of the lip elevators, and both contribute to the formation of the melolabial fold. Mechanical pressure on both zygomaticus muscles produces synergistic effects in the periorbital region, which is accentuated by pressure on the orbital orbicularis muscle, and all together contributes to the formation of radially oriented folds at the lateral cantus. The orbicularisoris is responsible for forceful lip closure and serves as a sphincter of the mouth. Pressure on this muscle induces folds that radiate perpendicularly to the vermilion border. This muscle is partly an antagonist of the lip elevators. The lip depressors include the orbicularis oris, mentalis, depressor angulioris, depressorlabii and platysma muscles. The levator labii superioris alaeque nasi muscle is a lip elevator and its contraction can, in some people, cause obliquely oriented wrinkles along the nasal dorsum and sidewall, after just 30 seconds of mechanical pressure [4].

Longitudinal studies confirm that persistent wrinkles evolve directly from temporary ones [5]. An imagebased method was developed which showed that a subjects' unique pattern of persistent facial wrinkles observed during a neutral expression at the age of 8 years was predicted by the pattern of temporary wrinkles observed while smiling [6]. Factors which contribute to facial wrinkle formation include genetic predisposition, environmental influences, habits, hyperdynamic facial expression, loss of underlying skeletal and soft tissue support, decreased skin elasticity, and gravitational force [7]. Underlying mechanical stress is an obligatory factor. If it is not present, as seen on the dorsal forearms, wrinkles do not form regardless of photo damage severity. The loss of the skins mechanical property is significantly faster on sun-exposed than on sun-protected areas [8]. Persistent facial wrinkle formation thus depends on both the cumulative amount of mechanical stress and reduced skin elasticity caused by aging and photo damage due to previous sun exposure. Ultraviolet (UV)-induced skin damage is thus not a cause but an accelerator of wrinkle formation [1].

Sleep lines are caused by repetitive and constant pressure of the face on a pillow during sleeping and body position importantly contributes to their formation [9]. People sleep approximately eight hours per day and when sleeping on one side of the body (or on the stomach), temporary sleeping lines become permanent after some time. Sleeping can cause irreversible damage to the dermis and adipose tissues in an individual and result in facial deformities. It exhibits long-term tension on the skin, which pushes or pulls the skin in a direction that is perpendicular to the direction of the muscles of the face. Gravitational force becomes very aggressive and causes the muscles to elongate. Permanent sleeping wrinkles often fade in morning in young, although they may be visible for several hours until the facial skin adopts its initial relaxed state. As we age, this interval prolongs, leading to permanently damaged soft tissue and permanent wrinkles.

The aim of our study was to investigate to what extent sleeping contributed to formation of facial wrinkles and whether sleeping on the specially designed pillow reduced them. We adopted methods from the study of Baek et al. to demonstrate that sleeping on the specially designed pillow reduced facial skin wrinkles [10].

\section{Materials and Methods}

\subsection{Participants}

A 28-day pilot study was carried out in which fifteen healthy female volunteers aged 23 - 55 years (mean age $35.6 \pm 8.5$ ) slept on our specially designed pillow. Inclusion criteria were that the volunteers were healthy Cau- 
casian women without pre-existing skin disease (including damaged skin, previous sunburn, tattoos, and scars), chronic diseases, pregnancy, or taking medication which could influence the skin response. Participants' wrinkles were measured before they started sleeping on the anti-wrinkle pillow (baseline) $\left(T_{0}\right)$ and then two $\left(T_{14}\right)$ and four $\left(\mathrm{T}_{28}\right)$ weeks afterwards when the experiment ended. None of the subjects had had invasive or non-invasive facial procedures in the past (surgical, laser, fillers, Botox, peelings). They were asked not to change any habits, which could influence the quality of the skin (e.g. sun exposure, extreme sport activities, alcohol and cigarette consumption, ingestion of antioxidants and food supplements, usage of cosmetics, etc.). No adverse reactions were observed or reported during the study. Measurements were performed under controlled and identical environmental conditions for all participants. The ambient temperature was maintained at $21^{\circ} \mathrm{C} \pm 3^{\circ} \mathrm{C}$ and the relative humidity in the range of $50 \% \pm 8 \%$. None of participants wore makeup and were allowed to relax on a comfortable diagnostic bed for some minutes before the pictures were taken. All pictures were taken between 12 p.m. and 3 p.m. The study was conducted during the period from June to July 2013, according to the Declaration of Helsinki Principles and was approved by the National Medical Ethics Committee of the Republic of Slovenia.

\subsection{Properties of the Anti-Wrinkle Pillow}

We evaluated the specially-designed pillow to reduce and improve facial wrinkles/deformities while sleeping. Standard pillows exert pressure on an individual's face when a user is lying in a prone position with the face pressed against a pillow, mostly on its central part. The pressure is thus generally unevenly dispersed and results in formation of the facial deformities and wrinkles, especially on the cheeks, around the eyes and the mouth where the pressure is highest (Figure 1(a)). The anti-wrinkle pillow was designed to redistribute pressure from the central face (the cheeks, eyes and mouth) to the chin and the forehead (Figure 1(b) and Figure 2). It has a central hole with a centric wire to regulate its size to suspend the user's face whilst sleeping and two different sides, which enable the user to choose according to the length of his/her neck for a proper neck support (Figure 2) [4].

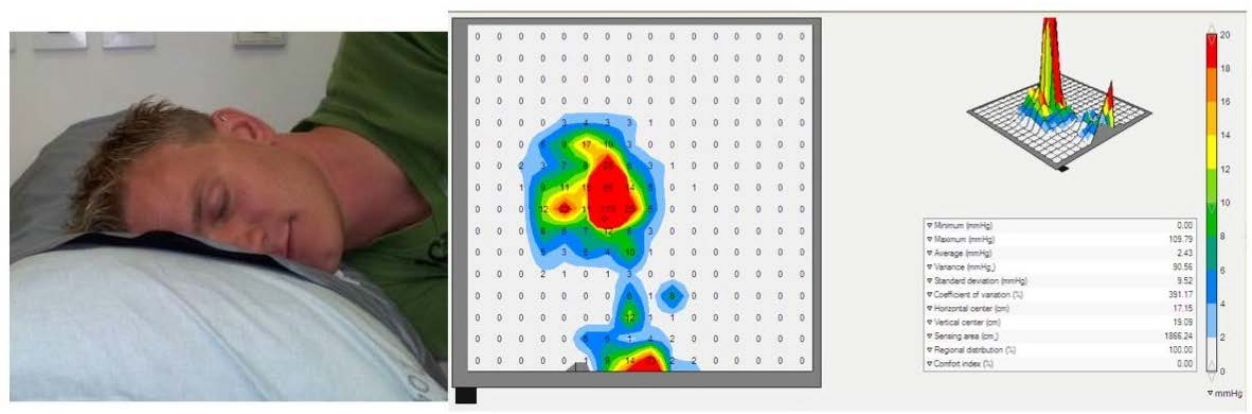

(a)

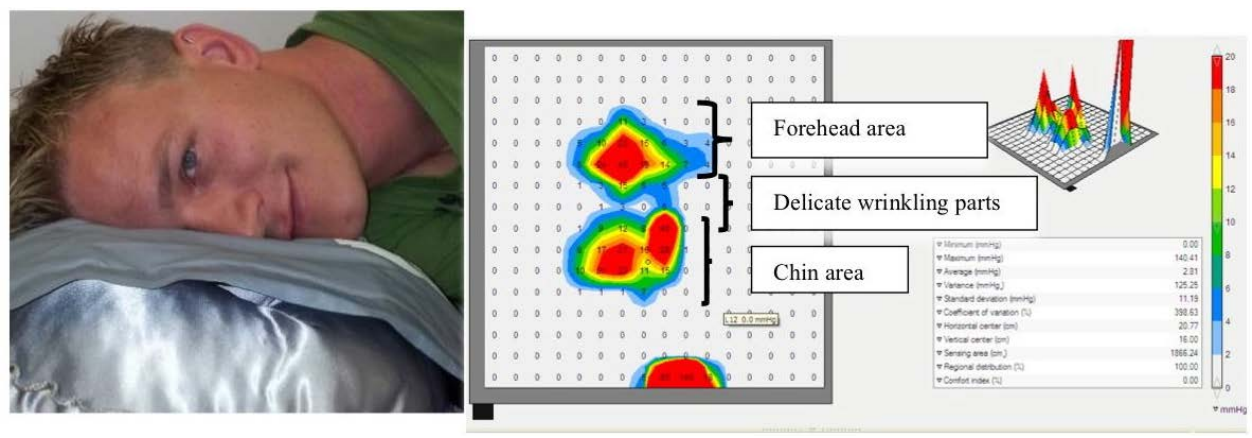

(b)

Figure 1. (a) and (b) Presentation of the force distribution on the face with standard and anti-wrinkle pillows. Redistribution of the pressure from delicate parts of the face to the chin and the forehead can be seen if sleeping on an anti-wrinkle pillow. The measurement of the pressure was done by mFLEX ${ }^{\circledR}$ instrument that evaluates the interaction between a human body and the surface that supports it. (a) Standard pillow; (b) Anti-wrinkle pillow. 


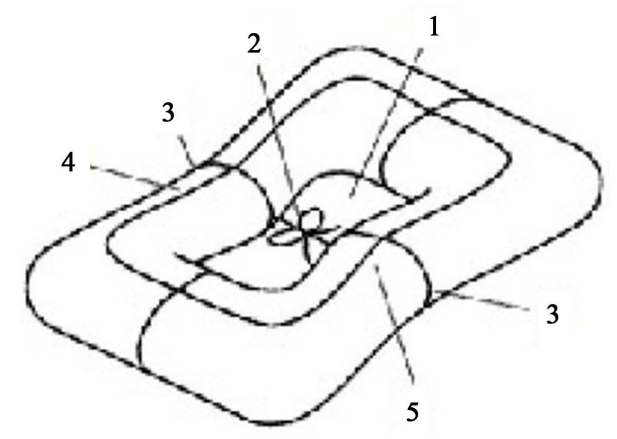

Figure 2. The specially designed anti-wrinkle pillow. Legend: 1: central hole; 2: centric wire; 3: variable filling; 4 and 5: different sizes (fillings), which enable more/less neck support.

\subsection{Facial Wrinkles Assessment}

Evaluation of facial wrinkles was conducted at baseline $\left(T_{0}\right)$, at two $\left(T_{14}\right)$ and at four $\left(T_{28}\right)$ weeks afterwards. Participants' faces were photographed by 2D Image Analysis Skin CT computerized camera (Meizy Beauty Equipment Manufacturer, China) and photographs were analysed with the built analysing software. This analysing system of 2D images allows fast, contact-free, and direct measurement of the skin surface topography in vivo and at high resolution. Severity of wrinkles was quantified as the wrinkle density (percentage of wrinkles per observed area), which was calculated by dividing the total wrinkle pixel area (marked with green dots and lines in Figure 3) by total pixels of the area of interest (outlined area in Figure 3) based on the default parameter settings from the manufacturer. All images were analysed by the red, green, and blue model (RGB), which is based on three independent primary colours, and the value of each component strongly depends on the light intensity of the image. The RGB system was used to minimize errors caused by irregular light intensity of images. The computer-based image analysis was used to identify and quantify facial wrinkles, since it is less artefact prone and more accurate method than the commonly used silicon replica technique [11] [12].

The surface of observed wrinkle areas (outlined with green dots/lines in Figure 3) on each subject's image was defined by standardized facial landmarks: both lateral canthuses, alar fibro-fatty tissue of the nose and corners of the mouth. This standardized surface was then used to assess subjects' images taken under same conditions in neutral and smiling facial expressions at $\mathrm{T}_{0}, \mathrm{~T}_{14}$, and $\mathrm{T}_{28}$ (Figure 3 ). The analysis was based on the relative change of facial wrinkles, since the relative change of wrinkles would reflect the efficiency of the anti-wrinkle pillow, which would thus allow the interpretation of the results more accurately than absolute values, with which each individual should have their own reference value. Reference values were defined separately for each individual before sleeping on pillow.

\subsection{Statistical Analysis}

Paired t-test analysis was conducted using R software program [13]. We analysed differences in wrinkle densities before commencing the study $\left(\mathrm{T}_{0}\right)$, two $\left(\mathrm{T}_{14}\right)$, and four $\left(\mathrm{T}_{28}\right)$ weeks afterwards. We analysed five facial areas separately (as described above) and all together.

\section{Results}

A statistically significant decrease in wrinkle density occurred 14 days of anti-wrinkle pillow use; around the right eye in neutral and smiling facial expressions, around the left eye whilst smiling and on average in all observed areas $(p<0.05)$ (Table 1$)$. Even greater differences were observed after 28 days (Table 2$)$ but they were not statistically significant when compared $\mathrm{T}_{14}$ and $\mathrm{T}_{28}$ (Table 3 ). All selected facial parameters showed statistically significant decrease in wrinkle densities after 28 days except the frontal area $(p=5.38)$. Results also showed that wrinkles decreased mostly around the right eye, the left eye while smiling and on average in all observed areas of the face (total area) regardless of the duration of the study $\left(\mathrm{T}_{14}\right.$ and $\left.\mathrm{T}_{28}\right)$. The average reduction of wrinkles in total investigated area of the face (expressed as the density of wrinkles per observed skin surface) was approximately $7 \%$ after 14 days, and $12 \%$ after 28 days. We also further tested whether there was a statistical difference between the sleeping position (left vs. right side of the body) and facial wrinkle improvement in 

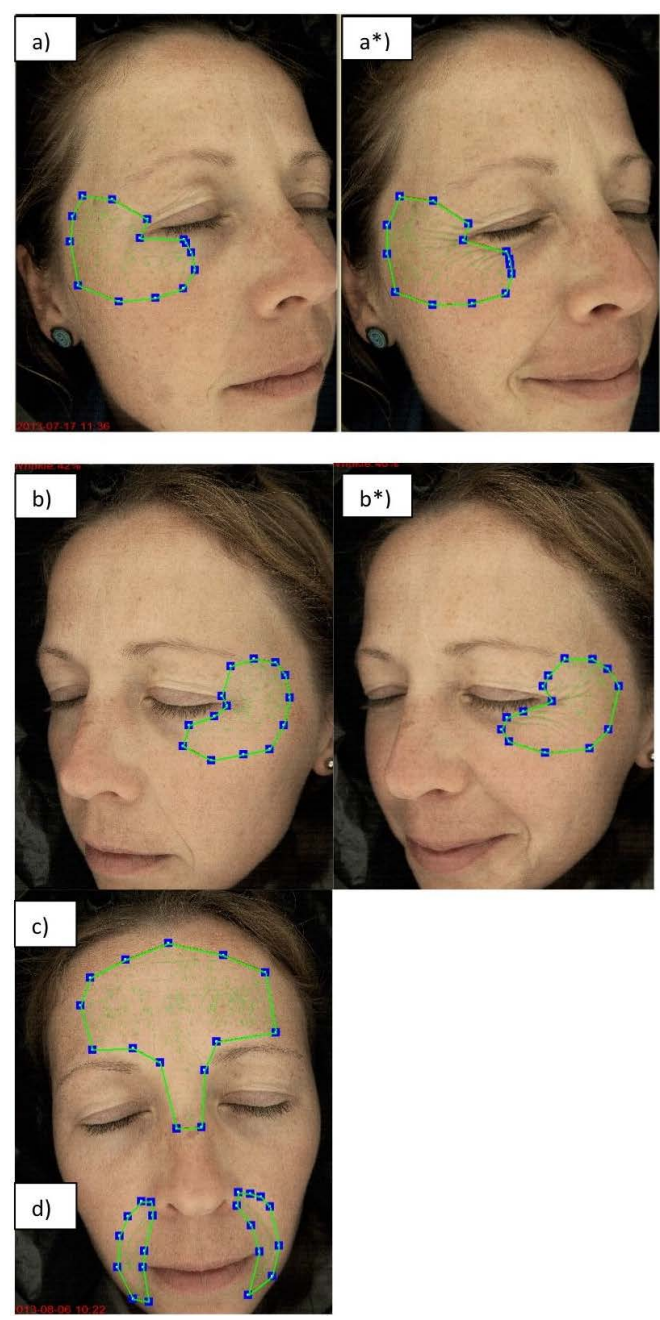

Figure 3. The face was divided into five observed wrinkle areas: around the right (a) and left eyes (b), frontal area (c); and both nasolabial folds (d). Pictures (a), (b), (c) and (d) were taken in a neutral relaxed expression of participants' faces (to assess persistent wrinkles), and $a^{*}$ and $b^{*}$ while smiling to assess temporary wrinkles. Five pictures of an each participant were analysed: one taken in a frontal view ((c) and (d)) and four in an oblique $45^{\circ}$ view ((a), (a*), (b), (b*)). The program detects the total pixels of the wrinkle area (marked with green dots), and the wrinkle density was calculated as the percentage of total pixels of the outlined area (marked with green lines).

Table 1. Wrinkles density at the baseline and following 14 days of sleeping on a pillow at different anatomical regions of the face.

\begin{tabular}{|c|c|c|c|c|c|c|c|}
\hline & \multirow{2}{*}{$\begin{array}{c}\mathrm{T}_{0} \\
\text { Average }\end{array}$} & \multirow{2}{*}{$\begin{array}{c}\mathrm{T}_{14} \\
\text { Average }\end{array}$} & \multirow{2}{*}{ Mean of the differences } & \multicolumn{2}{|c|}{ 95\% confidence interval } & \multirow{2}{*}{$\mathrm{t}$-value } & \multirow{2}{*}{$p$-value } \\
\hline & & & & Low & Upper & & \\
\hline Front & 46.26 & 45.85 & 0.71 & -4.60 & 6.03 & 0.29 & 0.7763 \\
\hline Eye right & 50.66 & 45.64 & 6.85 & 3.64 & 10.06 & 4.61 & $0.0005^{*}$ \\
\hline Eye right smile & 56.01 & 51.64 & 5.78 & 2.25 & 9.31 & 3.53 & $0.0036^{*}$ \\
\hline Eye left & 52.26 & 51.28 & 2.71 & -0.86 & 6.29 & 1.63 & 0.1251 \\
\hline Eye left smile & 65.20 & 57.35 & 10.07 & 4.51 & 15.63 & 3.91 & $0.0017^{*}$ \\
\hline Total area & 56.6 & 49.6 & 7.08 & 2.29 & 11.86 & 3.17 & $0.00679^{*}$ \\
\hline
\end{tabular}

Legend: $\mathrm{T}_{0}$ —baseline; $\mathrm{T}_{14}$-after 14 days of using a pillow; ${ }^{*} p<0.05$. 
Table 2. Wrinkle density at the baseline and following 28 days of sleeping on a pillow at different anatomical regions of the face.

\begin{tabular}{|c|c|c|c|c|c|c|c|}
\hline & \multirow{2}{*}{$\begin{array}{c}\mathrm{T}_{0} \\
\text { Average }\end{array}$} & \multirow{2}{*}{$\begin{array}{c}\mathrm{T}_{28} \\
\text { Average }\end{array}$} & \multirow{2}{*}{ Mean of the differences } & \multicolumn{2}{|c|}{ 95\% confidence interval } & \multirow{2}{*}{ t-value } & \multirow{2}{*}{$p$-value } \\
\hline & & & & Low & Upper & & \\
\hline Front & 46.26 & 47.35 & -0.71 & -3.15 & 1.72 & -0.63 & 0.5387 \\
\hline Eye right & 50.66 & 44.71 & 5.78 & 1.99 & 9.57 & 3.29 & $0.0057^{*}$ \\
\hline Eye right smile & 56.01 & 51.07 & 5.14 & 0.88 & 9.40 & 2.60 & $0.0216^{*}$ \\
\hline Eye left & 52.26 & 45.92 & 6.92 & 1.76 & 12.09 & 2.89 & $0.0124^{*}$ \\
\hline Eye left smile & 65.20 & 54.57 & 11.71 & 4.22 & 19.20 & 3.37 & $0.0049^{*}$ \\
\hline Total area & 56.6 & 44.4 & 12.20 & 1.76 & 15.46 & 2.69 & $0.01737^{*}$ \\
\hline
\end{tabular}

Legend: $\mathrm{T}_{0}$ —baseline; $\mathrm{T}_{28}$-after 28 days of using a pillow; ${ }^{*} p<0.05$.

Table 3. Wrinkle density after 14 and 28 days of sleeping on a pillow at different anatomical regions of the face.

\begin{tabular}{|c|c|c|c|c|c|c|c|}
\hline & \multirow{2}{*}{$\begin{array}{c}\mathrm{T}_{14} \\
\text { Average }\end{array}$} & \multirow{2}{*}{$\begin{array}{c}\mathrm{T}_{28} \\
\text { Average }\end{array}$} & \multirow{2}{*}{ Mean of the differences } & \multicolumn{2}{|c|}{ 95\% confidence interval } & \multirow{2}{*}{ t-value } & \multirow{2}{*}{$p$-value } \\
\hline & & & & Low & Upper & & \\
\hline Front & 45.85 & 47.35 & -3 & -6.94 & 0.94 & -1.65 & 0.1236 \\
\hline Eye right & 45.64 & 44.71 & l & -4.42 & 4.42 & 0 & 1.0000 \\
\hline Eye right smile & 45.64 & 44.71 & -0.61 & -5.85 & 4.62 & -0.25 & 0.8022 \\
\hline Eye left & 51.28 & 45.85 & 4.23 & -1.49 & 9.95 & 1.60 & 0.1335 \\
\hline Eye left smile & 57.35 & 54.57 & 2.78 & -5.31 & 7.92 & 0.43 & 0.6746 \\
\hline Total area & 49.6 & 44.4 & 5.2 & -7.95 & 11.01 & 0.34 & 0.7339 \\
\hline
\end{tabular}

Legend: $\mathrm{T}_{14}$-after 14 days of using a pillow; $\mathrm{T}_{28}$-after 28 days of using a pillow; ${ }^{*} p<0.05$.

neutral and smiling facial expressions after sleeping on the anti-wrinkle pillow for 28 days. To test this hypothesis, participants were divided into two groups, those who reportedly sleep predominantly either on the left or on the right side of the body. Sleeping habits of participants were as follows: twelve participants reported that they sleep predominantly on the left or both sides of the body, six predominantly on the right or both sides, eleven on both sides, three on their stomach, and one on her back (Table 4 and Table 5). Results did not reveal statistically significant reduction in wrinkle density in a neutral facial expression, however, wrinkle density decreased around the left periocular area in participants who claimed to sleep predominantly on their left (or both) side of the body while smiling, and the difference was statistically significant (Table 5) $(p=0.0490)$. Finally, we investigated if sleeping position influences overall density of facial wrinkles. To test this hypothesis, participants were divided into two groups, those who sleep predominantly on either side of their bodies and those who sleep on their backs and/or stomachs. Total wrinkle area was compared in both groups at time $\mathrm{T}_{0}$ and $\mathrm{T}_{28}$ and average improvement/reduction of facial wrinkles was evaluated (Table 6). Those participants who sleep on either side of their bodies (left or right) $(\mathrm{N}=11)$ showed statistically significant reduction in total wrinkle improvement $(p$ $=0.0109)$ compared to those who sleep on their back $(\mathrm{N}=1)$ and stomach $(\mathrm{N}=3)$.

\section{Discussion}

Stegman postulated for the first time in his paper "Sleep Creases" published in 1987 the likely aetiology of sleeping creases, which he observed to form diagonally on the cheeks and the lower face and vertically on the forehead [14]. It was noticed later that sleeping wrinkles can also manifest as the nasolabial folds and as "crow’s feet” around the eyes. Stegman also noticed that sleeping wrinkles are different than wrinkles caused by sun damage, due to smoking, frowning or laughing, since they are caused by specific sleeping behaviour and become deepened over time if sleeping patterns do not change. His theory was later confirmed by Fulton and Gaminchi [15] and Sarifakioğlu et al. [9]. 
Table 4. Comparison of sleeping position (left vs. right side of the body) and wrinkle improvement/reduction at the both periocular areas in a neutral facial expression after sleeping on an anti-wrinkle pillow for 28 days.

\begin{tabular}{|c|c|c|c|c|c|c|c|}
\hline & \multirow{2}{*}{$\begin{array}{c}\Delta \mathrm{T}\left(\mathrm{T}_{0}-\mathrm{T}_{28}\right) \\
\text { Left eye } \\
\text { Average }\end{array}$} & \multirow{2}{*}{$\begin{array}{c}\Delta \mathrm{T}\left(\mathrm{T}_{0}-\mathrm{T}_{28}\right) \\
\text { Right eye } \\
\text { Average }\end{array}$} & \multirow{2}{*}{$\begin{array}{l}\text { Mean of the } \\
\text { differences }\end{array}$} & \multicolumn{2}{|c|}{ 95\% confidence interval } & \multirow{2}{*}{ t-value } & \multirow{2}{*}{$p$-value } \\
\hline & & & & Low & Upper & & \\
\hline $\begin{array}{l}\text { Sleeping on the right or } \\
\text { both sides }(\mathrm{N}=6)\end{array}$ & 5.83 & 6.66 & -0.83 & -8.61 & 6.94 & -0.27 & 0.7941 \\
\hline $\begin{array}{l}\text { Sleeping on the left or } \\
\text { both sides }(N=12)\end{array}$ & 8.25 & 7.25 & 1 & -4.06 & 6.06 & 0.434 & 0.6721 \\
\hline
\end{tabular}

Legend: $\Delta \mathrm{T}$-average change of wrinkles' densities; ${ }^{*} p<0.05$.

Table 5. Comparison of sleeping position (left vs. right side of the body) and wrinkle improvement/reduction at both periocular areas while smiling after sleeping on an anti-wrinkle pillow for 28 days.

\begin{tabular}{|c|c|c|c|c|c|c|c|}
\hline & \multirow{2}{*}{$\begin{array}{c}\Delta \mathrm{T}\left(\mathrm{T}_{0}-\mathrm{T}_{28}\right) \\
\text { Left eye smile } \\
\text { Average }\end{array}$} & \multirow{2}{*}{$\begin{array}{c}\Delta \mathrm{T}\left(\mathrm{T}_{0}-\mathrm{T}_{28}\right) \\
\text { Right eye smile } \\
\text { Average }\end{array}$} & \multirow{2}{*}{$\begin{array}{l}\text { Mean of the } \\
\text { differences }\end{array}$} & \multicolumn{2}{|c|}{ 95\% confidence interval } & \multirow{2}{*}{ t-value } & \multirow{2}{*}{$p$-value } \\
\hline & & & & Low & Upper & & \\
\hline $\begin{array}{l}\text { Sleeping on the right or } \\
\text { both side }(N=6)\end{array}$ & 9.33 & 3.33 & 6 & -12.8 & 24.8 & 0.016 & 0.4513 \\
\hline $\begin{array}{l}\text { Sleeping on the left or } \\
\text { both side }(\mathrm{N}=12)\end{array}$ & 14.58 & 6.08 & 8.5 & -67.3 & -18.8 & -5.663 & $0.0490^{*}$ \\
\hline
\end{tabular}

Legend: $\Delta \mathrm{T}$-average change of the wrinkle density; ${ }^{*} p<0.05$.

Table 6. Comparison of sleeping position (left/right side of the body vs. back/stomach) and total wrinkle improvement/ reduction.

\begin{tabular}{|c|c|c|c|c|c|c|c|}
\hline & $\begin{array}{c}\Delta \mathrm{T}\left(\mathrm{T}_{0}-\mathrm{T}_{28}\right) \\
\text { Sleeping on either side }\end{array}$ & $\begin{array}{c}\Delta \mathrm{T}\left(\mathrm{T}_{0}-\mathrm{T}_{28}\right) \\
\text { Sleeping on back or stomach }\end{array}$ & \multirow{2}{*}{$\begin{array}{l}\text { Mean of the } \\
\text { differences }\end{array}$} & \multicolumn{2}{|c|}{ 95\% confidence interval } & \multirow{2}{*}{ t-value } & \multirow{2}{*}{$p$-value } \\
\hline & Average & Average & & Low & Upper & & \\
\hline $\begin{array}{l}\text { Total wrinkle } \\
\text { improvement }\end{array}$ & 9.63 & 5.8 & 8.5 & -67.3 & -18.8 & -5.66 & $0.0109^{*}$ \\
\hline
\end{tabular}

Legend: $\Delta \mathrm{T}$ — change in average percentage of wrinkles; ${ }^{*} p<0.05$.

According to Hillebrand et al., age at onset and rate of persistent facial wrinkles depend on both, the cumulative amount of mechanical stress (frequency of temporary wrinkles) and reduced skin elasticity due to cumulative harmful environmental influences, such as sun exposure [1]. The skin progressively loses its elasticity due to decreased synthesis of procollagen I and III, reduced elastin gene expression in the dermis, and decreased proliferative capacity of the skin cells and intercellular matrix synthesis [16] [17]. Considering that most people sleep about one third of their life, prolonged and repeated distortion of their facial skin will eventually lead to premature wrinkle formation. Nasolabial folds and wrinkles around periocular areas are particularly noticeable on mornings after waking up. The depth of wrinkles usually reduces during day because the gravity causes the cheeks to pull down the skin around the eyes thereby reducing wrinkles. However, continuous and repetitive pressure on the face during sleeping leads to formation of permanent wrinkles. Fulton and Gaminchi observed that sleep lines were related to facial attachments of the superficial musculoaponeurotic system and recommended to release them with a carbon dioxide laser in order to achieve a good clinical outcome [15]. We present an alternative solution to reduce sleep-related facial deformities and wrinkles while sleeping. Sleeping on a specially designed pillow resulted in significant decrease in wrinkle density. The average reduction in total investigated area of the face (expressed as the density of wrinkles per observed skin surface) was approximately $7 \%$ after 14 days, and 12\% after 28 days (Table 1 and Table 2). Similar results were obtained by Beak et al., who demonstrated that sleeping on pillowcases which contained copper-impregnated fibres, reduce depth of skin wrinkles by approximately 9\% [10]. On the other hand, improvement in wrinkle density at frontal area of the face (the nasolabial folds and the forehead) could not be observed, although we expected deterioration of oblique wrinkles located unilaterally on the left and right side of the forehead, since the pillow was not designed to release the pressure of the forehead. Two possible explanations would be that participants were too young and 
had too elastic skin and that evaluation was made hours after waking up when temporary wrinkles disappeared. Since evaluation of frontal pictures included the forehead and nasolabial folds together, the possible improvement in nasolabial folds and/or deterioration in forehead wrinkles could not be observed because we did not analyse those two regions of the face separately. The further improvement in wrinkle density after sleeping on a pillow from a $2^{\text {nd }}$ week to a $4^{\text {th }}$ week (comparison of $T_{14}$ and $T_{28}$ ) could also not be observed (Table 3 ), most probably because wrinkles become less noticeable already after few days of cessation of the pressure on delicate parts of the face and did not improve further. We also found in our study that those participants who were sleeping on either side of their bodies (left or right) showed statistically significant reduction in total wrinkle density compared to those who were sleeping on their back and stomach. This could mean that people who sleep predominantly on their left or right side of the body could benefit more from using the anti-wrinkle pillow compared to those who sleep predominantly on their back or stomach. Furthermore, wrinkle density improved around the left periorbital area in participants who reportedly sleep predominantly on their left side of the body while smiling but not in relaxed facial expression. In those participants we demonstrated improvement of temporary wrinkles despite of their relatively young age when one does not expect dramatic decrease in skin elasticity and severe sun damage. This further supports the benefit of an anti-wrinkle pillow. We did not observe any correlation between reduction in wrinkle density and age of participants most likely because age differences of our participants were too small to observe dramatic reduction in skin elasticity.

\section{Conclusion}

Sleeping on the specially designed pillow results in a significant reduction of facial skin wrinkle density. Redistribution of the mechanical stress on the delicate areas of the face during sleep can significantly slow down the rate and extent of facial wrinkles formation, especially in users who tend to sleep predominantly on sides of their bodies. The anti-wrinkle pillow may represent an effective method to prevent sleeping wrinkles.

\section{Acknowledgements}

Authors would like to thank Florian Probst for his valuable comments. Pillows were donated by Maremico, d.o.o. The first author declares the following: Prof. Dr. Borut Poljsak is a consultant for the company Maremico, d.o.o. All other authors do not report any conflicts of interest. No grants or other financial assistance was provided for the study.

\section{References}

[1] Hillebrand, G.G., Liang, Z., Yan, X. and Yoshii, T. (2010) New Wrinkles on Wrinkling: An 8-Year Longitudinal Study on the Progression of Expression Lines into Persistent Wrinkles. British Journal of Dermatology, 162, 1233-1241. http://dx.doi.org/10.1111/j.1365-2133.2010.09709.x

[2] Puizina-Ivic, N. (2008) Skin Aging. Acta Dermatovenerologica Alpina, Panonica et Adriatica, 17, 47-52.

[3] Miyamoto, K. and Hillebrand, G.G. (2007) The Influence of Facial Expression on the Age-Dependent Changes in Facial Wrinkling. Journal of Society of Cosmetic Science, 58, 206-207.

[4] Poljsak, B., Godic, A., Lampe, T. and Dahmane, R. (2012) The Influence of the Sleeping on the Formation of Facial Wrinkles. Journal of Cosmetic and Laser Therapy, 14, 133-138. http://dx.doi.org/10.3109/14764172.2012.685563

[5] Hillebrand, G.G. and Demirli, R. (2009) Method and Apparatus for Realistic Simulation of Wrinkle Aging and DeAging. U.S. Patent Application 20090028380A1.

[6] Hillebrand, G.G., Levine, M.J. and Miyamoto, K. (2001) The Age-Dependent Changes in Skin Condition in African Americans, Caucasians, East Asians, Indian Asians and Latinos. IFSCC Magazine, 4, 259-266.

[7] Zimbler, M.S., Kokoska, M.S. and Thomas, J.R. (2001) Anatomy and Pathophysiology of Facial Aging. Facial Plastic Surgery Clinics of North America, 9, 179-187.

[8] Jemed, G.B.E., Selvaag, E., Agren, M. and Wulf, H.C. (2001) Measurement of the Mechanical Properties of Skin with Ballistometer and Suction Cup. Skin Research and Technology, 7, 122-126. http://dx.doi.org/10.1034/j.1600-0846.2001.70211.x

[9] Sarifakioğlu, N., Terzioğlu, A., Ates, L. and Aslan, G. (2004) A New Phenomenon: "Sleep Lines” on the Face. Scandinavian Journal of Plastic and Reconstructive Surgery and Hand Surgery, 38, 244-247. http://dx.doi.org/10.1080/02844310410027257 
[10] Baek, J.H., Yoo, M.A., Koh, J.S. and Borkow, G. (2012) Reduction of Facial Wrinkles Depth by Sleeping on Copper Oxide-Containing Pillowcases: A Double Blind, Placebo Controlled, Parallel, Randomized Clinical Study. Journal of Cosmetic Dermatology, 11, 193-200. http://dx.doi.org/10.1111/j.1473-2165.2012.00624.x

[11] Friedman, P.M., Skover, G.R., Payonk, G., Kauvar, A.N. and Geronemus, R.G. (2002) 3D In-Vivo Optical Skin Imaging for Topographical Quantitative Assessment of Non-Ablative Laser Technology. Dermatologic Surgery, 28, 199204.

[12] Jacobi, U., Chen, M., Frankowski, G., Sinkgraven, R., Hund, M., Rzany, B., et al. (2004) In Vivo Determination of Skin Surface Topography Using an Optical 3D Device. Skin Research and Technology, 10, 207-214. http://dx.doi.org/10.1111/j.1600-0846.2004.00075.x

[13] R Development Core Team (2012) R: A Language and Environment for Statistical Computing. R Foundation for Statistical Computing, Vienna. http://www.R-project.org/

[14] Stegman, S.J. (1987) Sleep Creases. American Journal of Cosmetic Surgery, 4, 277-280.

[15] Fulton, J.E. and Gaminchi, F. (1999) Sleep Lines. Dermatologic Surgery, 25, 59-62. http://dx.doi.org/10.1046/j.1524-4725.1999.08073.x

[16] Varani, J., Warner, R.L., Gharaee-Kermani, M., Phan, S.H., Kang, S., Chung, J.H., et al. (2000) Vitamin A Antagonizes Decreased Cell Growth and Elevated Collagen-Degrading Matrix Metalloproteinases and Stimulates Collagen Accumulation in Naturally Aged Human Skin. Journal of Investigative Dermatology, 114, 480-486. http://dx.doi.org/10.1046/j.1523-1747.2000.00902.x

[17] Poljsak, B., Dahmane, R. and Godic, A. (2012) Intrinsic Skin Aging: The Role of Oxidative Stress. Acta Dermatovenerologica Alpina, Panonica et Adriatica, 21, 33-36. 